\title{
Determination of Mesalazine Spectrophotometry Based on The Charge Transfer Complex n- $\pi$ Using Reagent p-bromanil
}

\author{
Ghaith Luqman Sadeeq Al-Ramadhani Sobhi Mohsen Jarallah Al-Mtioti \\ Department of Chemistry, College of Education for Pure Sciences, University of \\ Mosul, Mosul / Iraq \\ Received Accepted \\ 25/09/2018 07/11/2018
}

\begin{abstract}
Simple, sensitive and rapid spectrophotometric method for the determination of mesalazine in pure form and pharmaceutical preparations is described. The method is based on the reaction of mesalazine with p-bromanil in the presence of borate buffer solution of $\mathrm{pH} 9$ to form a pink color charge transfer complex of maximum absorption peak $\left(\lambda_{\max }\right)$ at $346 \mathrm{~nm}$. Under the optimized reaction conditions, Beer's law correlating the absorbance with mesalazine concentration was obeyed in the range of 0.48-12 $\mu \mathrm{g} \mathrm{ml}^{-1}$. The molar absorptivity was $6.5 \times 10^{3} \mathrm{~L} \cdot \mathrm{mol}^{-1} \mathrm{~cm}^{-1}$. The limits of detection was $0.053 \mu \mathrm{g} \mathrm{ml}{ }^{-1}$. The accuracy and precision of the method were satisfactory; the average recovery was $98.04 \%$ and values of relative standard deviations better than $1.70 \%$. The stoichiometry of the reaction was studied, and the reaction mechanism was postulated. The proposed method was successfully applied to the determination of mesalazine in its pharmaceutical tablet and capsule with good accuracy and precisions. The results obtained by the proposed method were compared with those obtained by the official method.
\end{abstract}

Keywords: Spectrophotometry; Charge transfer complex; mesalazine; p-bromanil 


\title{
تقدير الميزالازين طيفياً بالاعتماد على معقد الثحنة المنتقلة باستعمال كاشف بارا- برومانيل
}

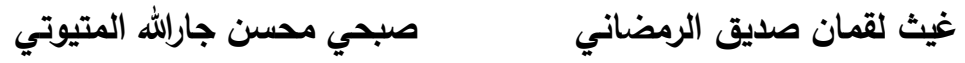

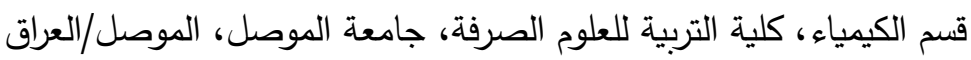

$$
\text { تاريخ الاستلام } \quad \text { 2018/09/25 }
$$



تم وصف طريقة طيفية سهلة وحساسة لتقدير الميزالازين بشكله النقي وفي مستحضراته الصيدلانية (الأقراص والكبسول). تعتمد الطريقة على التفاعل بين الميزالازين والكاشف بارا- برومانيل بوجود محلول البورات المنظم عند دالة حامضية pH9 مكونا معقد الثحنة المنتقلة ذي لون ارجواني يمتلك أقصى امتصاص له عند 346 نـانوميتر ـ أمكن تطبيق قـانون بير ضـمن مدى التراكيز 0.48-12 مـايكروغرام/ملتر في حين كانت


الاسترجاع 98.04\% في حين كان الانحراف القياسي النسبي أفضل من 1.70\%. تمت دراسة طبيعة المعقد فكانت 1:1 وميكانيكية التفاعل. طبقت الطريقة بنجاح في تقدير الميزالازين في مستحضراته الصيدلانية بثكل أقراص وكبسول بدقة وتوافق جيدين. كما تم مقارنة الطريقة المقترحة مع الطريقة القياسية في الدستور البريطاني. الكلمات المفتاحية: المطياف الضوئي ، معقد الثحنة المنتقلة ، ميزالازين ، بارا- برومانيل.

\section{المقدمة}

الميزالازين (حسب التسمية البريطانية) ويعرف ايضاً باسم الميزلامين (حسب التسمية الامريكية) او 5امينو حامض السالسيليك (5-ASA) وحسب التسمية النظامية 5- امينو -2- هيدروكسي حامض البنزويك[1]. ويعد الميزالازين من الادوية المضادة للالتهابات اذ يستعمل في علاج التهاب الامعاء، المتضمنة التهاب تقرح القولون او التهاب الشرج و المستقيم ويحمي من امراض Crohn's، وذلك من خلال منع تطور امراض السرطان عند الاشخاص الذين يعانون من التهاب الامعاء [2]. وللميزالازين تأثثرات جانبية اولها الغازات المعوية بالإضافة الى صداع واسهال والآم البطن. ولم تسجل اي دراسات عند النساء الحوامل ولكن وجد تراكيز من الدواء في مستخلص حليب المرضعات. يجب تجنب اعطاء دواء الميزالازين للأطفال تحت سن سنتين وللأشخاص الذين يعانون من امراض الكلى وكذلك الاشخاص الذين لديهم حساسية من الاسبرين [3]. 
الميزالازين يكون بشكل مسحوق بلوري ابيض الى وردي ـ قليل الذوبان في الماء البارد والكحول ، يذوب بشدة في الماء الحار وكذلك في حامض الهيدروكلوريك ويمتلك الميزالازين الصيغة الكيميائية جزيئي 153.135 غم. مول-1 وله الصيغة الكيميائية المبينة في الثكل (1)[4].

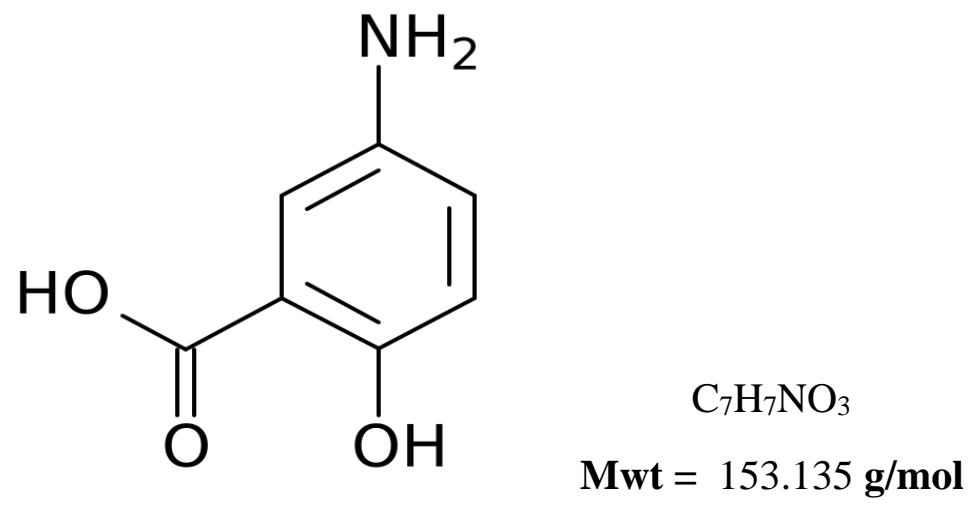

الشكل (1) الصيغة الكيميائية للميزالازين

استعملت العديد مـن الطرائق التحليليـة المختلفـة لتقدير الميزالازين بشكله النقي ومستحضـراته الصيدلانية و

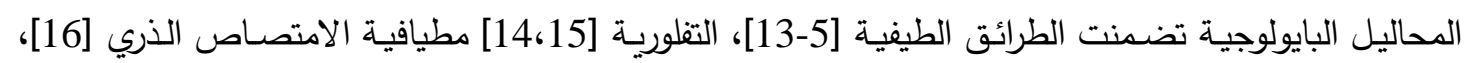
فولتامتري النبضي المشتق[17] وتقنية كروماتوغرافيا السائل عالي الاداء [18-22]. ان الطريقة المقترحة هي طريقة سهلة، دقيقة، حساسة واقتصادية لتقدير الميزالازين طيفياً بشكله النقي

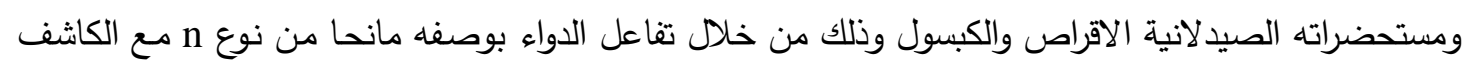
بارا- برومانيل بوصفه مستقبلا من نوع $\pi$ في المحلول المائي ليعطي معقد شحنة منتقلة.

\section{الجزء العملي}

الأجهزة المستخدمة:

Shimadzu UV-1800 PC, UV-Visible double- تم استعمال جهاز المطياف الضوئي Spectrophotometer مع خلايا كوارتز ذات عرض 1سم، فضلاً عن جهاز قياس الدالة الحامضية نوع Thermo RL 060P Electron Company-Singapore مائي نوع BS-11 Lab Companion-Korea، واجريت عمليات الوزن باستعمال ميزان حساس نوع KERN ABS-Germany نوعOWER SONIC 405 Lab Tech-Korea من أجل زيادة سرعة عملية الإذابة في تحضير الدحاليل. 
كل المواد المستعملة في البحث كانت على درجة عالية من النقاوة ومصنعة من قبل شركات عالمية

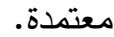

محلول الميزالازين القياسي (100 مايكروغرام/مللتر): حضر المحلول بإذابة 0.01 غرام من الميزالازين النقي في كمية من الايثانول وخفف المحلول بالماء المقطر في قنينة حجمية سعت 100 مللتر. استعمل هذا المحلول في تحضير محاليل مخفقة بالماء المقطر عند الحاجة اليها. محلول بارا- برومانيل (10×10 مولاري): حضر بإذابة 0.0424 غرام من البرومانيل في 100 مللتر

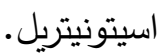
محلول البورات المنظم pH9 (0.05 مولاري): حضر بإذابة 1.904 غرام من بورات الصوديوم الرباعية في 100 مللتر من الماء المقطر . لمار محلول الكاربونات المنظم pH9 : حضر من مزج 10 ملتر بتركيز 0.1 مولاري من كاربونات

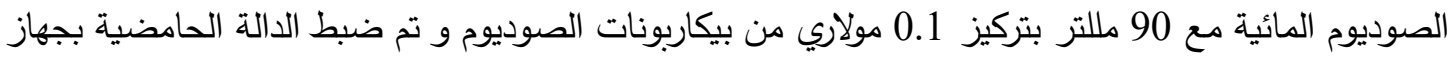
. $\mathrm{pH}$ meter محلول هيدروكسيد الصوديوم (0.1 مولاري): حضر المحلول بإذابة 0.4 غرام في 100مللتر ماء

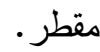
محلول حامض الهيدروكلوريك (0.1 مولاري): حضر بتخفيف 1ملتر من الحامض المركز (10 مولاري) في 100 مللتر من الماء المقطر . ماهن.

تم اضافة كميات متزايدة من المركب الدوائي الميزالازين (0.48-12) مايكروغرام/مللتر، يتبعها اضافة

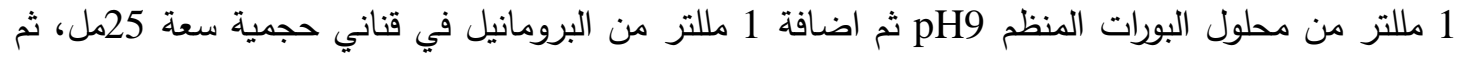
اكمال الحجم بالماء المقطر الى حد العلامة. تركت المحاليل في حمام مائي عند 40 مُ لمدة 60 دقيقة وتم قياس


المديات الدذكورة اعلاه يتبعها انحراف سالب عن القانون.

محاليل المستحضرات الدوائية: تم مزج محتوى 6 كبسولات او طحن عشرة اقراص من المستحضرات الدوائية للميزالازين ووزنها. وتم وزن ما يكافئ 400 ملغم (محتوى كبسولة واحدة) او500 ملغم (محتوى قرص دوائي واحد) من الدواء الى قنينة حجمية سعة 250 مل وإذابتها بكمية قليلة من الايثانول ثم اكمل الحجم الى حد العلامة بالماء المقطر ورشح المحلول للحصول على 1600 مايكروغرام/مل من الكبسول او 2000 مايكروغرام/مل من الاقراص الدوائية والتي استعملت لتحضير محلول 100 مايكروغرام/مللتر من الميزالازين، اتبعت طريقة العمل الموصوفة اعلاه. 


\section{النتائج وإلمناقشة}

طيف الامتصاص النهائي:

تتضمن الطريقة تفاعل الميزالازين مع الكاشف بارا- برومانيل بوجود محلول البورات المنظم (pH9)

ليعطي معقد شحنة منتقلة ذات لون بنفسجي يمتلك اقصى امتصاص عند 346 نانوميتر ، والذي تم استعماله في القياسات اللاحقة، وكما موضح في الثكل (2) والذي يظهر ان للمحلول الصوري اقصى امتصاص عند 317 نانوميتر و امتصاص قليل عند 346 نانوميتر ·

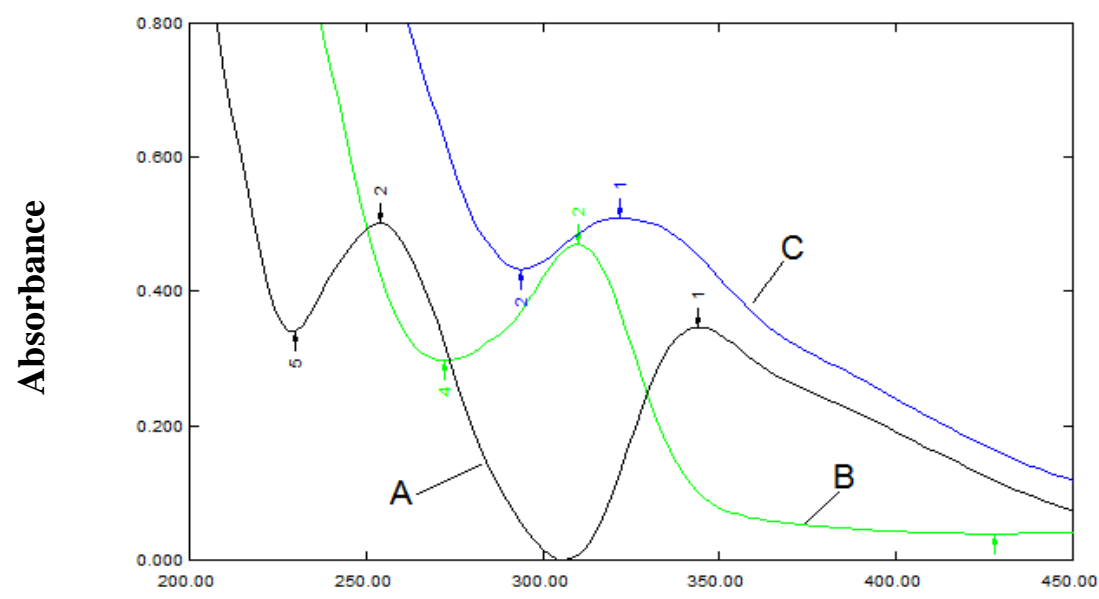

Wavelength (nm)




لمعقد الميزالازين مع كاشف بارا- برومانيل ضد الماء المقطر تحت الظروف المثلى.

وتمـت دراسـة الظـروف المثلى اللازمـة لتكوين المعقد ميزالازين - بـارا- برومانيـل وذلك بتغيير احــ المعطيات وتثبيت الاخرى ودراسة تأثيرها على امتصاص المعقد وكما موضح شرحها في الفقرات التالية: تأثير المذيب تم دراسـة انواع مختلفـة من المذيبات مثل الماء، الميثانول، الايثانول والاسيتونيتريل كوسط للتفاعل وللحصول على حساسية عالية واستقرار للمعقد. ووجد ان استعمال الماء كمذيب للدواء والاسيتونيتريل كمذيب للبرومانيل وبوجود 1 عياري من هيدروكسيد الصوديوم والتخفيف بالماء المقطر هو الوسط المناسب للتفاعل وتكوين المعقد الثكل (3) وقد تم استعمال هذا النظام من المذيبات في الخطوات اللاحقة. 




Wavelength (nm)

الثكل (3) تأثير مذيب الاسيتونيتريل على (A) امتصاص 10 مايكروغرام/مللتر من الميزالازين مع كاشف بارا- برومانيل

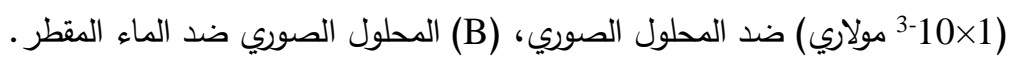

تأثير الدالة الهيدروجينية والمحاليل المنظمة

تم دراسة تأثير دوال حامضية مختلفة تراوحت بين 7-10 باستعمال محلولي 0.1 عياري من حامض pH9 الهيدروكلوريك أو هيدروكسيد الصوديوم. وقد وجد ان المعقد يعطي اقصى امتصاص عند دالة هيدروجينية مع ازاحة حمراء ليعطي المعقد افضل امتصاص عند 346 نانوميتر باستعمال هيدروكسيد الصوديوم الشكل (4). كما تم دراسة تأثير استعمال محاليل منظمة عند دالة هيدروجينية pH9 محضرة من محلول البورات المنظم والكاربونات المنظم وقد وجد ان استعمال (1مل) من محلول البورات المنظم يعطي للمعقد اقصى امتصاص الثكل (5) و(6). (1) (2)

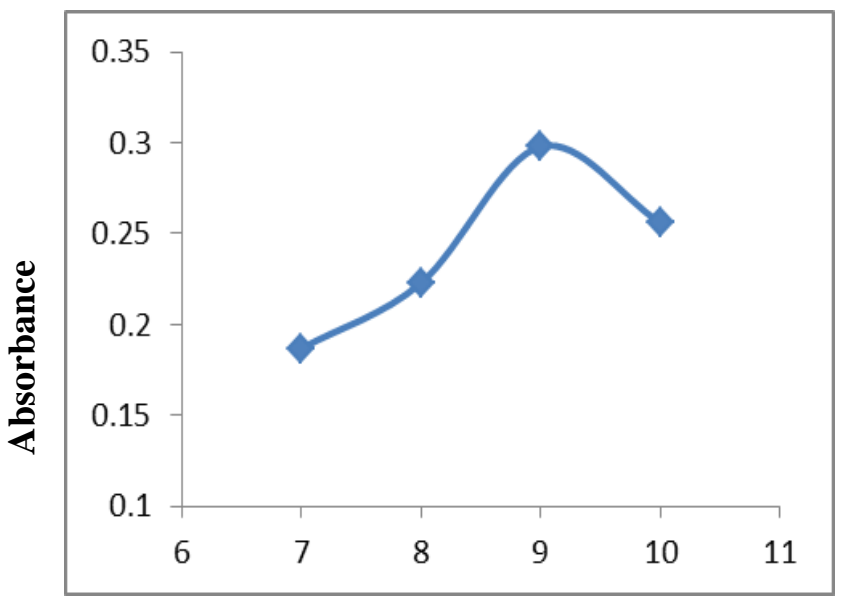

pH

8 الثكل (4) تأثير الدالة الحامضية على امنصاص 8 مايكروغرام/مللتر من الميزالازين

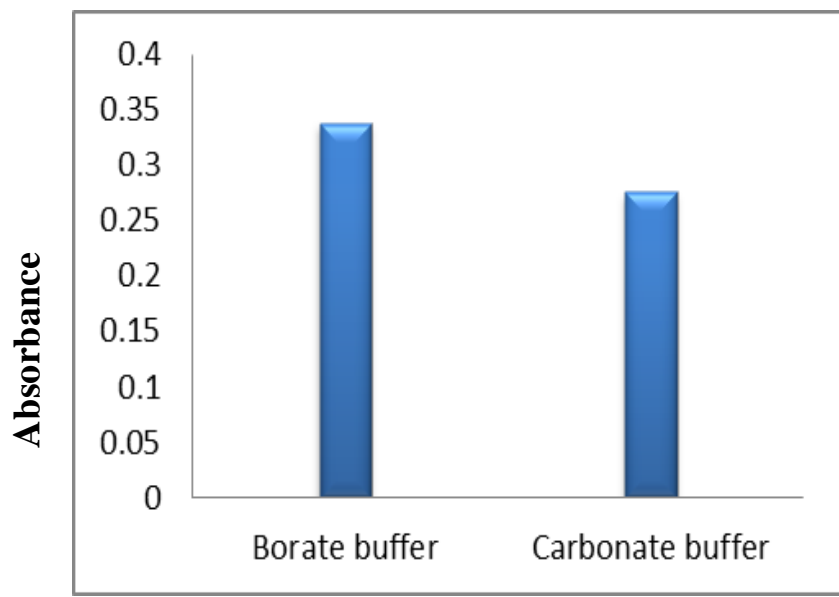

\section{buffer solution}

الثكل (5) تأثير المحاليل المنظمة على امتصاص 8 مايكروغرام/مللتر من الميزالازين 


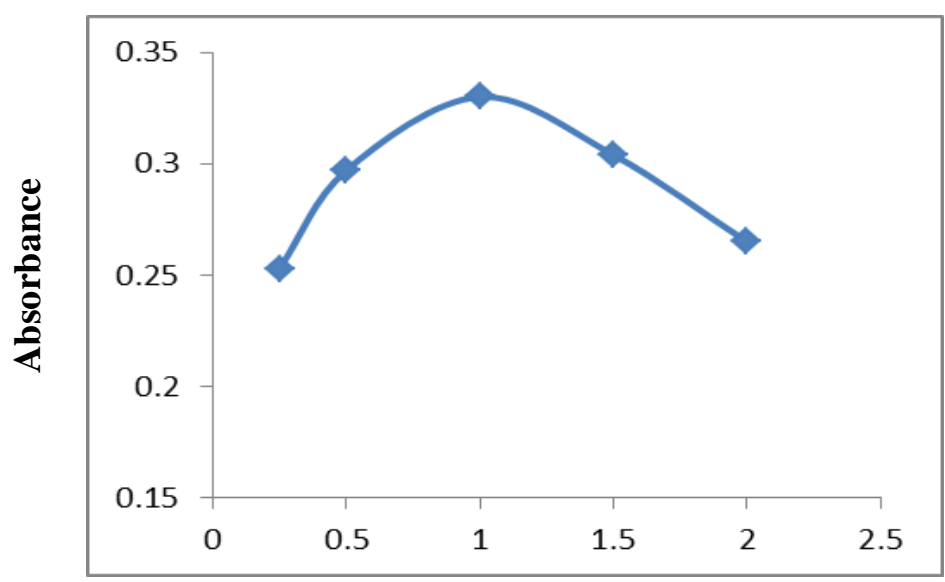

Borate buffer,pH9, ml

الثكل (6) تأثير حجم محلول البورات المنظم على امتصاص 8 مايكروغرام/مللتر من الميزالازين

دراسة تأثير تركيز الكاشف بارا- برومانيل

تم دراسة تأثير تراكيز مختلفة (0.5×10-3 -2.5×10-3 مولاري) من البرومانيل للحصول على افضل

امتصاص للمعقد، وقد وجد ان استعمال (1مل) من تركيز 1×10-3 مولاري من البارا- برومانيل يعطي افضل مديل

شدة امتصاص للمعقد الثكل (7 و8). وقد تم استعمال هذه الظروف في التجارب اللاحقة.

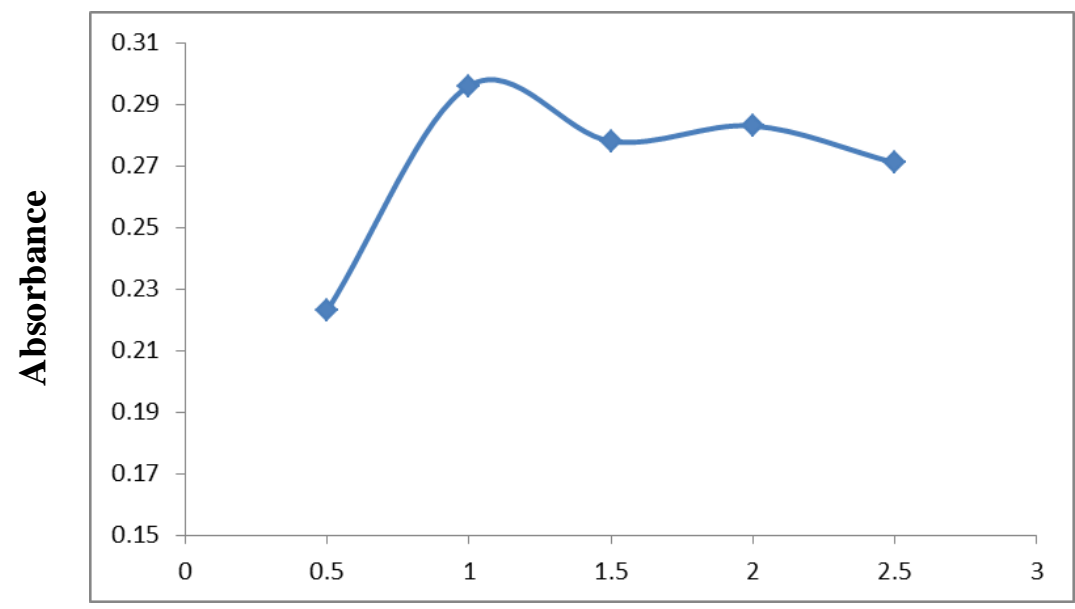

p-Bromanil Conc. $\times 10^{-3} \mathrm{M}$

الثكل (7) تأثير تركيز كاشف البارا- برومانيل على امتصاص 8 مايكروغرام/مللتر من الميزالازين 


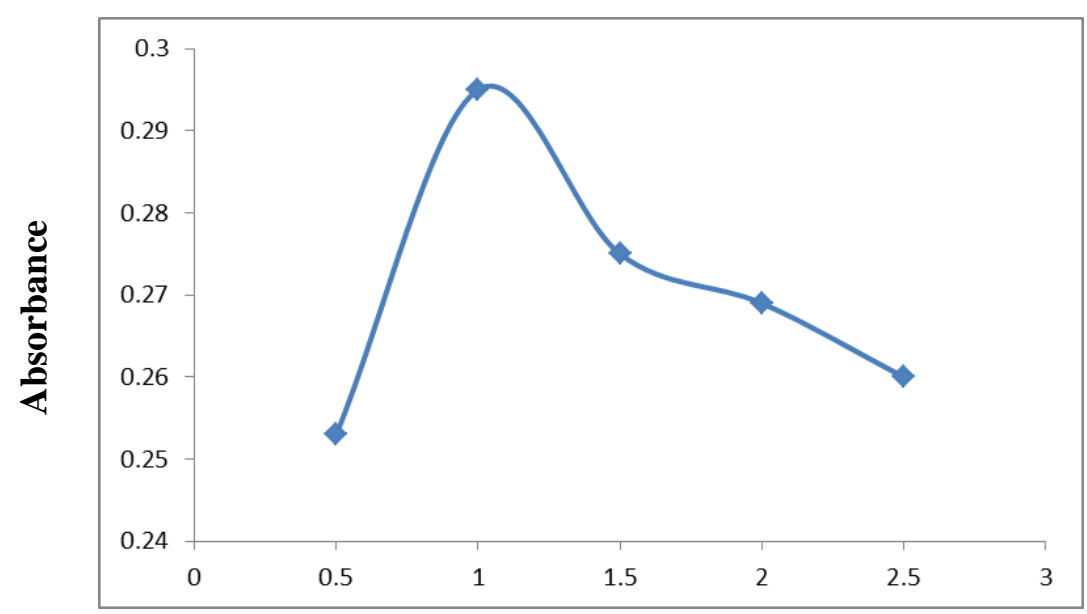

p-Bromanil, $1 \times 10^{-3} \mathrm{M}, \mathrm{ml}$

الثكل (8) تأثير حجم كاشف البارا- برومانيل على امتصاص 8 مايكروغرام/مللتر من الميزالازين

دراسة تأثير درجة الحرارة وزمن الاستقرار لتكوين المقد

تم دراسة تأثير الزمن اللازم لتكوين واستقرار المعقد عند درجات حرارية مختلفة تراوحت بين درجة حرارة

الغرفة (20م) و 45ْم وذلك بمتابعة امتصاص المعقد ضد محلوله الصوري عند أزمان بين 5 و 200 دقيقة.

وقد اعطى المعقد اعلى امتصاص بعد 60 دقيقة عند درجة حرارة 40ْم وبزمن استقرار 30 دقيقة الثكل (9) والتي استعملت في الدراسات اللاحقة.

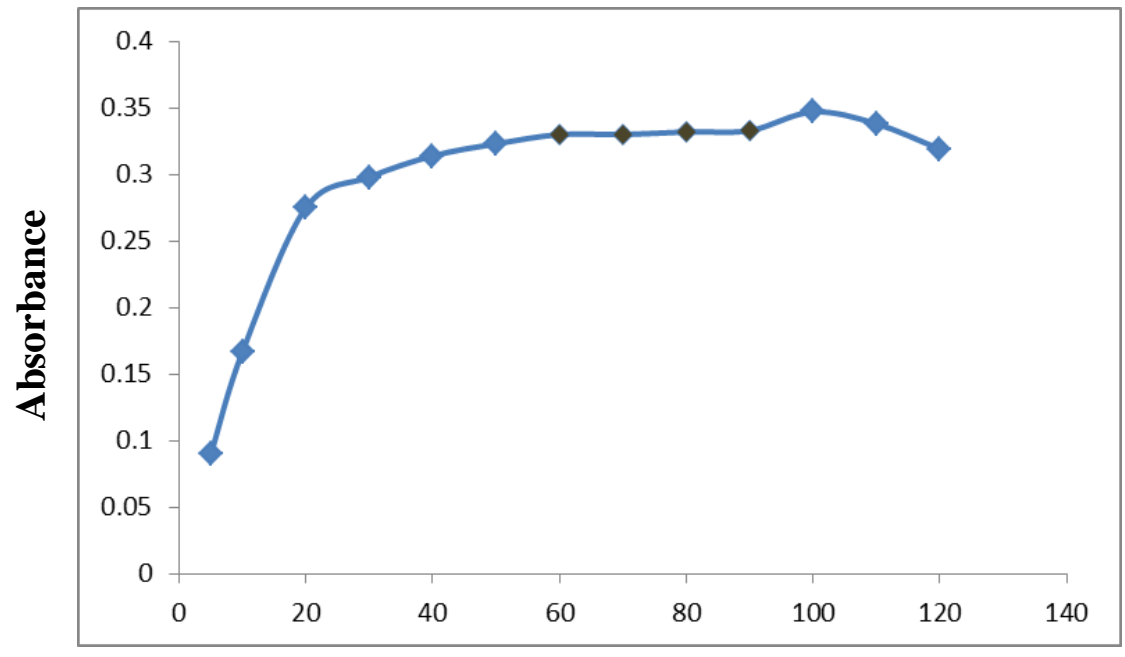

Time (min)

الشكل (9) تأثير درجة الحرارة على امتصاص 8 مايكروغرام/مللتر من الميزالازين مع بارا- برومانيل في 40ْ 
تأثير تسلسل الاضافة

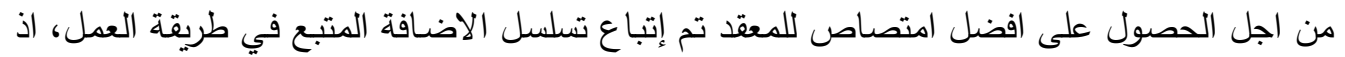
اعطت إضافات التسلسلات الاخرى انخفاضاً واضحاً في قيمة امتصاص المعل فئد.

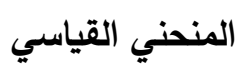

من خـلال الشكل (10) تم ايجاد حدود قانون بير للطريقـة والامتصاصية المولاريـة والتي تثير الىى حساسية الطريقة العالية، بالإضافة الى معامل الارتباط والذي يشير الى المواصفات الخطية للمنحني القياسي. كما تم حساب الانحراف القياسي النسبي والاسترجاعية لستة مكررات لثلاث تراكيز مختلفة والتي تثير الى دقة وتوافق الطريقة. وتم حساب حد الكثف والذي كانت قيمته اوطئ من اقل قراءة على الهنحني (الجدول 1).

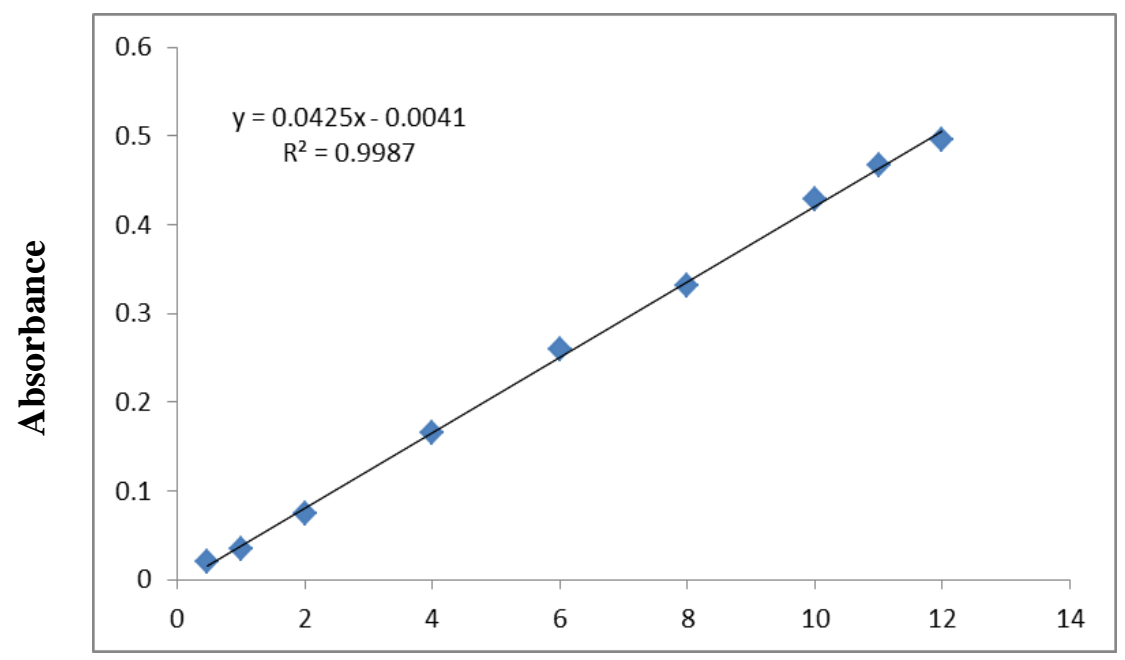

Concentration of mesalazine ( $\mu \mathrm{g} / \mathrm{ml})$

الثكل (10) المنحني القياسي لتقدير الميزالازين

جذول (1) ملضص الخصائص الطيفية والبيانات الاحصائية للطريقة المقترحة

\section{القيم المقاسة للطربقة المقترحة}

Beer's law limits $\left(\mu \mathrm{g} \mathrm{ml}^{-1}\right)$

Molar absorptivity $\left(1 . \mathrm{mol}^{-1} \cdot \mathrm{cm}^{-1}\right)$

$0.48-12$

LOD $\left(\mu \mathrm{g} \cdot \mathrm{ml}^{-1}\right)$

$6.5 \times 10^{3}$

LOQ $\left(\mu \mathrm{g} \cdot \mathrm{ml}^{-1}\right)$

0.053

Average recovery $(\%)^{* *}$

0.176

Correlation coefficient $\left(\mathrm{R}^{2}\right)$

98.04

Regression equation $(Y) *$

0.9987

Slope, $a$

Intercept, $b$

0.0041

$\mathrm{RSD}^{* *}$

$\leq 1.70$

$* Y=a X+b$, where $X$ is the concentration of mesalazine in $\mu \mathrm{g} \mathrm{ml}^{-1}$. $* *$ Average of six determinations. 
تم دراسة تأثير المتداخلات لبعض من مواد السواغ التي غالبا ما يتم اضافتها من قبل الشركات

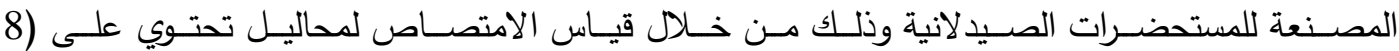
مايكروغرام/ملتر ) من الميزالازين وكميات مختلفة من مواد السواغ في قناني حجمية سعة 25مل. وقد وجد انه لا يوجد تداخل لمواد السواغ الا في حالة اضافة كميات كبيرة منها الجدول(2). جدول (2) تأثير مواد السواغ على المركب الدوائي

\begin{tabular}{|c|c|c|c|c|c|}
\hline \multirow{2}{*}{ Foreign Compound } & \multicolumn{5}{|c|}{ Recovery of $8 \mu \mathrm{g} \mathrm{ml}{ }^{-1}$ of mesalazine per $\mu \mathrm{g} / \mathrm{ml}$} \\
& 50 & 100 & 150 & 200 & 250 \\
\cline { 2 - 6 } & 100.9 & 102 & 103.7 & 105.4 & 106.3 \\
\hline Glucose & 101.2 & 102.1 & 103 & 105.2 & - \\
\hline Lactose & 99.4 & 100.3 & 105.4 & 109.6 & - \\
\hline Starch & 100.9 & 99.6 & 97.8 & 95.1 & 92.4 \\
\hline Sodium chloride & 103 & 104.2 & 105.6 & - & - \\
\hline Arabic Gum & & \multicolumn{5}{c}{} \\
\hline
\end{tabular}

نسبة تركيب المعقد وثابت الاستقرار

تم دراسة نسبة تركيب المعقد المتكون بين الميزالازين وكاشف بارا- برومانيل بتطبيق طريقتي التغيرات



مولاري). وتثير النتائج الى ان المعدد متكون بنسبة 1:1 من الميزالازين الى الكاشف الثكل (11). وهذا يدل ان معقد الثحنة المنتقلة من نوع $n$ قد تكون من خلال مجموعة الامينو لمركب الميزالازين.


لمعقد الميزالازين (6×6 10 -4) مولاري وكاشف بارا - برومانيل

الثكل (11) النسبة المولية (a) والتغيرات المستمرة (b)

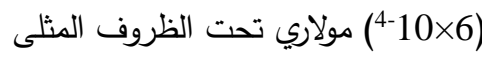


وتم حساب ثابت الاستقرار للمعقد من خلال مقارنة الامتصـاص لمحلول يحتوي على كميات متكافئة

مـن الميـزالازين وكاشـف بـارا- برومانيـل (As) الـى محلـول يحتـوي علـى زيـادة مـن البرومانيـل (الكميـة المثلى)(Am). اذ تم استعماله حسب المعادلة التالية بالاعتماد على النسبة 1:1

$$
\begin{gathered}
\mathrm{Kc}=(1-\alpha) / \alpha^{2} \mathrm{C} \\
\alpha=(\mathrm{Am}-\mathrm{As}) / \mathrm{Am}
\end{gathered}
$$

حيث Kc هو ثابت الاستقرار (لتر .مول-1-) وم هي درجة التفكك و C تركيز المعقد والمساوية لتركيز

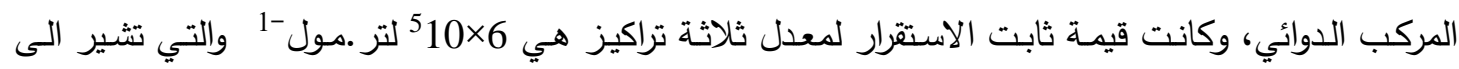
استقراريـة عالية للمعقد.

\section{ميكانيكية التفاعل}

ان تفاعل تكوين معقد الثـحنة المنتقلة بين الامينـات بوصفها مانحات مـن نـوع و والكاشف بـارابرومانيل بوصفه مستقبلا من نوع $\pi$ في المحلول المائي هي تفاعلات غير واضحة بثكل كامل. على كل حال في هذا البحث فـإن المعقد النـاتج في المحلول المـائي تكون بنسبة 1:1 بعد اضـافة الميزالازين الذي يمتلك مجموعـة امينو اولية الى كاشف البرومانيل في وسط قاعدي pH9 والذي اعطى اعلى امتصـاص عند 346 نانوميتر • فيما يعطي كاشف البرومانيل اقصى امتصاص عند 317 نانوميتر في وسط قاعدي pH9 والذي ربما يعود الى تكوين tribromohydroxy-p-benzoquinone [24] · والذي يعمل ككاشف تعقيد مـع المركب الدوائي. ان الانتقال الجزئي للمزدوج الاككتروني من المانح الى المستقبل ربما يحدث مع تكوين جذر حر ملون ذي معامل امتصاص عالٍ. وبالاعتماد على ذلك فقد تم اقتراح الميكانيكية الاتية:<smiles>O=C1C(Br)=C(Br)C(=O)C(Br)=C1Br</smiles>

Bromanil Tribromohydroxy-p-benzoquinone

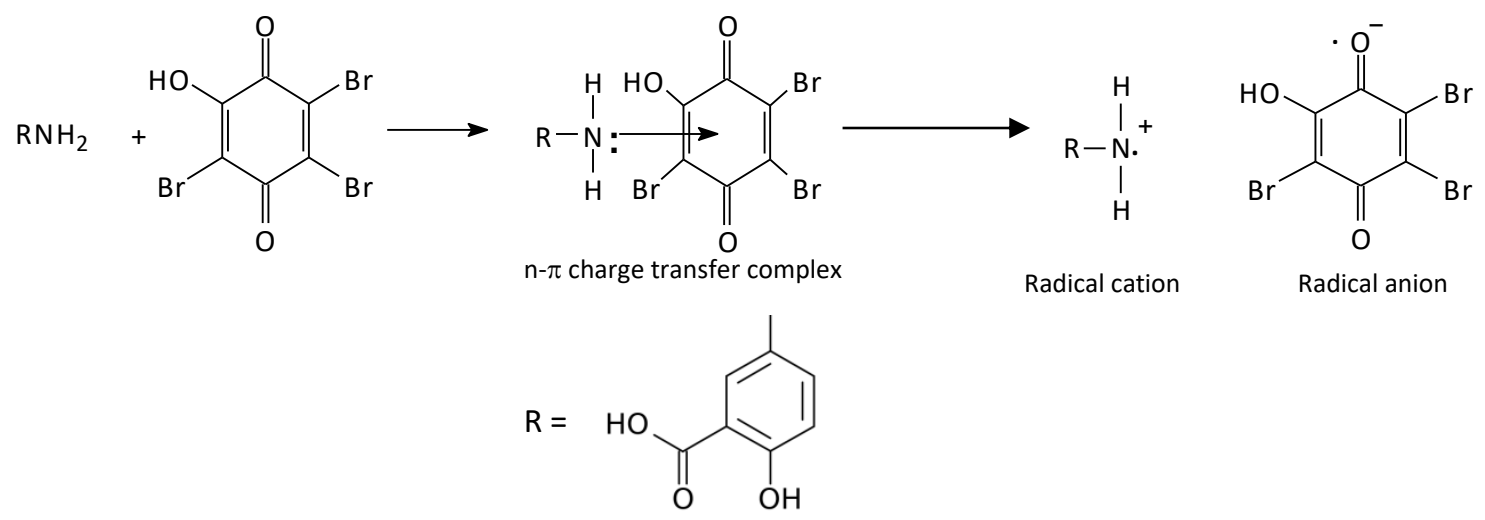

التوضيح (1) الميكانيكية المقترحة لتفاعل تكوين معقد الشحنة المنتقلة بين بارا- برومانيل و الميزالازين 


\section{تطبيق الطريقة المقترحة على المستحضرات الصيدلانية}

تم تطبيق الطريقة المقترحة بنجاح في تقدير الميزالازين في مستحضراته الصيدلانية على هيأة اقراص وكبسول. اذ تم مقارنة النتائج احصائيا من خلال حساب t-test للتعبير عن دقة الطريقة وحساب F-test للتعبير عن توافقها بالمقارنة مع الطريقة المعتمدة في الدستور البريطاني (طريقة التسحيح الجهدي) [25] عند مستوى ثقة 95 لثلاث درجات حرية كما موضح في الجدول (3). وتظهر النتائج ان قيم t- test و F-test هي اقل من القيم النظرية (F=9.28 ، t=3.18) [26]، وهذا يشير الى انه لا يوجد اختلاف معنوي بين الطريقة المقترحة والطريقة المعتمدة.

جدول (3) تقدير الميزالازين في المستحضرات الصيدلانية باستخدام الطريقة المقترحة والمقارنة مع الطريقة المعتمدة

\begin{tabular}{|c|c|c|c|c|c|c|}
\hline $\begin{array}{l}\text { Procedure } \\
\text { applied }\end{array}$ & $\begin{array}{c}\text { Pharmaceutical } \\
\text { preparation }\end{array}$ & $\begin{array}{c}\text { Drug } \\
\text { amount } \\
\text { present ( } \mu \mathrm{g} \\
\left.\mathrm{ml}^{-1}\right)\end{array}$ & $\begin{array}{l}\text { Recovery }{ }^{\mathrm{a}} \\
(\%)\end{array}$ & $\begin{array}{l}\text { Drug } \\
\text { content } \\
\text { found } \\
\text { (mg) }\end{array}$ & $\begin{array}{l}\text { Average } \\
\text { recovery } \\
(\mathrm{mg})\end{array}$ & $\begin{array}{l}\text { Certified } \\
\text { value } \\
(\mathrm{mg})\end{array}$ \\
\hline \multirow[b]{2}{*}{$\begin{array}{l}\text { Proposed } \\
\text { method }\end{array}$} & $\begin{array}{c}\text { Pentasa } \\
\text { Tablet / Ferring } \\
\text { AS/ Turkey }\end{array}$ & $\begin{array}{l}1 \\
4 \\
8\end{array}$ & $\begin{array}{c}98.8 \\
100.35 \\
99.4\end{array}$ & $\begin{array}{c}494 \\
501.7 \\
497\end{array}$ & $\begin{array}{c}497.56 \\
(0.28,2.39)^{b}\end{array}$ & $500 \mathrm{mg}$ \\
\hline & $\begin{array}{c}\text { Mesacol } \\
\text { Capsule } \\
\text { /universal } \\
\text { pharmaceutical } \\
\text { industries- } \\
\text { Unipharma/ } \\
\text { Syria }\end{array}$ & $\begin{array}{l}1 \\
4 \\
8\end{array}$ & $\begin{array}{c}98 \\
98.87 \\
99.03\end{array}$ & $\begin{array}{c}392 \\
395.5 \\
396.12\end{array}$ & $\begin{array}{c}394.54 \\
(2.81,2.02)^{b}\end{array}$ & $400 \mathrm{mg}$ \\
\hline
\end{tabular}

${ }^{a}$ Average of three determinations.

${ }^{\mathrm{b}}$ Figures in parenthesis are the calculated values for $t$, and $F$ respectively.

\section{الاستتتاج}

ان الطريقة الطيفية المقترحة ذات حساسية عالية (يمكن تقدير كميات ضئيلة من الميزالازين)، وذات دقة

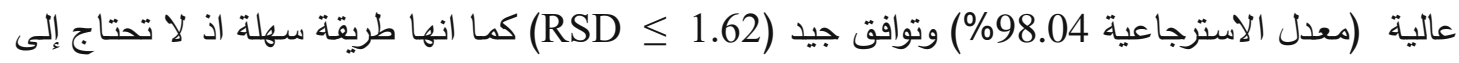
استعمال وسط عضـوي او الى استخلاص. كمـا ان الطريقـة المقترحـة طبقت بنجـاح لتقدير المركب الدوائي المدروس في مستحضراته الصيدلانية على هيأة اقراص وكبسول. 
1- Actis.GC, Pllicano.R and Rizzetto.M, "Individually administered or coprescribed thiopurines and mesalamine for inflammatory bowel disease" .World J Gastroenterol 15;1420-1426,(2009).

2- Sandborn.WJ, Feagan.BG and Lichtenstein.GR, "Medical management of mild to moderate Crohn's disease : evidence based treatment algorithms for induction and maintenance of remission"; Aliment Pharmacol Ther 26:987,(2007).

3- US National Library of Medicine 8600 Rockville Pike,Bethesda,MD 20894 US Department of Health and Human Service National Institutes of Health Page Last updated May (2018) .

4- Finkel, Cubeddu and Clark; Lippincott's Illustrated Reviews: Pharmacology, 4th Edition; 393,( 2009).

5- Al-Shreify.Z.A.M, "Development of spectrophotometric and fluorophotometric methods for determination of phenolicand nitrogenic drug compounds",M.Sc. Thesis, Mosul University, (2012).

6- Abdalla.F.A.A and Elbashir.A.A, "Development and validation of spectrophotometric methods for the determination of mesalazine in pharmaceutical formulation", J.Med.Chem, 4(3),361-366.,11,(2014).

7- Zakaria.R.A, "Spectrophotometric determination of Mesalazine by 8-hydroxyquinoline and N-(1-naphthyl)ethylene- diaminedihydrochl oride reagents in bulk and capsule dosage forms", J. Sci.,24(1),146-158,(2013).

8- Al-Enzy.M.S, Al-Sabha.T.N and Al-Ghabsha.T.S, "Use of charge transfer complex reaction in spectrophotometric micro Determination of some drugs", Jord. J. Chem., 7,87-102,(2012).

9- Al-Sabha.T.N, Al-Enizzi.M.S and Al-Taee.O.A, "Application of chloranil and fluoranil $\pi$-acceptors for the Spectrophotometric determination of mesalamine in pharmaceuticals", Eur. Chem. Bull., 3(4),377-383,(2014).

10- Salih.E.S and Al-Sharook.M.M, "Spectrophotometric assay of mesalazine in pharmaceutical preparation via oxidative coupling reaction with thymol and sodium metaperiodate", J.Edu.\&Sci.,21, 103-115,(2008).

11- Al-Fakhry.M.H.A, "The use of oxidative coupling reaction for spectrophotometric determination of aniline and its substituents and the drugs dipyrone and mesalazine", M.Sc.Thesis, Mosul University, 64-79,(2006).

12- Al-Daoudi.N.M.I, "Spectrophotometric determination of some drugs by using prussic blue reaction and methylene blue and rhodamine-B dyes", M.Sc.Thesis, Mosul University,62-119,(2011).

13- Al-Nuaimi. I. K. O, "Development of spectrophotometric and fluoro photometric methods for determination of some drug compounds ,M.Sc.Thesis, Mosul University,(2017).

14- Gui.F.L, Li.W, Fan.Y.C and Hu.Z-D, "Fluorescence spectroscopy studies on 5aminosalicylic acid and zinc 5-aminosalicylate with human serum albumin", J.Pharm.Biomed.Anal.,39,189- 197,(2004).

15- Al-Abdaly. Z. Z. S, "Development of Spectrophotometric ,Spectro fluorometric and High-performance Liquid ChromatographicMethods for Determination of some Drug Compounds", Ph.D.Thesis, Mosul University,(2013).

16- AL-Meshaekhy.M.Y,"Development of spectrophotometric methods and atomic absorption in drug compounds analysis using different reactions ",Ph.D. Thesis, Mosul University,(2017). 
17- Nigoric.B and Imunic.B, "Determination of 5-amino salicylic acid in pharmaceutical formulation by differential pulse voltammetry", J. Pharm. Biomed. Anal.,31,169-174,(2003).

18- Rao.K.H, Rao.A.L and Sekhar.K.C, "Validated PR-HPLC method for the estimation of mesalazine in bulk and tablet dosage form", Int. J. Res. Pharm. Chem., 3, 472- 480,(2013).

19- Elmasry. M. S, Blagbrough. I. S, Rowa. M. G and Saleh. H. M, "Quantitative HPLC analysis of mebererine, mesalazine, sulphasalazine and dispersible aspirin stored in avenalink monitored dosage system with co-prescribed medicine", J.Pharm. Biomed. Anal.,54, 646-652,(2011).

20- Abdolmohammad- Zadeh. $\mathrm{H}$ and Kohansal. S, "Determination of mesalamine by spectrofluorometry in human serum after solid-phase extraction with Ni-AL layered double hydroxide as a nanosorbent", J. Braz. Chem. Soc.,23,473781,(2012).

21- Pastorini. E, Locatelli. M, Simoni. P, Roda. G and Roda. E, "Development and validation of an HPLC-ESI- MS/MS method for determination of 5aminosalicylic acid its major- metabolites $\mathrm{N}$-acetyl-5-aminosalicylic acid in human plasma", J. Chromatogr. B, 872, 99- 106,(2008).

22- Rafael.J.A, Jobar.J.R , Gasagrande.R and Geargetti.S.R, "Validation of HPLC, DPPH and nitrosation methods for mesalamine determination in pharmaceutical dosage forms", Braz.J. Pharm. Sci., 43,(2007).

23- Skoog.D.A, West.D.M, Holler.F.J and Crouch.S.R, "Fundamentals of Analytical Chemistry", $9^{\text {th }}$ ed. Mary Finch,USA,(2013).

24- Townshend.A, "Analytical applications of molecular complexes", Proc. Soc. Anal. Chem.,

25- British pharmacopeia, CD-ROM, (2015).

26- Harevy.D, "Modern Analytical Chemistry", McGarw-Hill Higher Education,USA,(2000). 